ORIGINAL ARTICLE

\title{
Occupational exposure of midwives to nitrous oxide on delivery suites
}

\author{
K A Henderson, I P Matthews, A Adisesh, A D Hutchings
}

See end of article for

authors' affiliations

Occup Environ Med 2003;60:958-961

.....................

Correspondence to: Dr I P Matthews, Department of Epidemiology, Statistics and Public Health, University of Wales College of Medicine, Heath Park, Cardiff $\mathrm{CF} 14$ 4XN, UK; matthewsip@ cf.ac.uk

Accepted 17 December 2002

\begin{abstract}
Aims: To compare environmental and biological monitoring of midwives for nitrous oxide in a delivery suite environment.

Methods: Environmental samples were taken over a period of four hours using passive diffusion tubes. Urine measurements were taken at the start of the shift and after four hours.

Results: Environmental levels exceeded the legal occupational exposure standards for nitrous oxide (100 ppm over an 8 hour time weighted average) in 35 of 46 midwife shifts monitored. There was a high correlation between personal environmental concentrations and biological uptake of nitrous oxide for those midwives with no body burden of nitrous oxide at the start of a shift, but not for others.

Conclusions: Greater engineering control measures are needed to reduce daily exposure to midwives to below the occupational exposure standard. Further investigation of the toxicokinetics of nitrous oxide is needed.
\end{abstract}

$\mathrm{N}$ itrous oxide is used as an analgesic during labour. A number of epidemiological studies have linked occupational exposure to nitrous oxide with spontaneous abortions, congenital abnormality, and reduced rates of fertility, including reported effects in midwives. ${ }^{1-7}$ The evidence is equivocal due to problems associated with verification of exposure and validation of reproductive events. Nevertheless this evidence, as well as the known effects of nitrous oxide on folate synthesis, has influenced the setting of occupational exposure standards (OES).

In the UK the (OES) set for nitrous oxide is $100 \mathrm{ppm}$ over an eight hour time weighted average (TWA). ${ }^{8}$ There are also requirements to have 5-6 air changes per hour within delivery rooms ${ }^{9}$ to control levels of waste anaesthetic gas. High levels of nitrous oxide have been reported in delivery rooms, ${ }^{10-11}$ and a previous survey of levels of nitrous oxide in healthcare facilities had identified midwifery suites as being a particular problem. ${ }^{12}$ This made use of direct reading instrumentation, and so was expensive in manpower resource; it was therefore decided to investigate the potential usefulness and acceptability of passive environmental sampling to measure exposures in midwifery.

In order to obtain a better estimate of personal health risk, the measurement of uptake has been proposed. The most widely accepted method of biological sampling is measurement of urinary excretion, and a number of studies have looked at levels of urinary nitrous oxide using gas chromatography. ${ }^{13-18}$ A biological exposure index (BEI) of $55 \mu \mathrm{g} / \mathrm{l}$ for nitrous oxide has been recommended in urine, as this is the biological value which was obtained after four hours of an average environmental exposure to $100 \mathrm{ppm} .{ }^{19}$ It was therefore also decided to explore the relation between exposure and uptake.

\section{METHODS}

In hospital 1, 15 midwife shifts were monitored, two of which were the same individual. In hospital 2, 35 midwife shifts were monitored; 20 individuals were monitored on one occasion only, four individuals were monitored on two occasions, one on three occasions, and one on four occasions.
In order to deliver samples to the laboratory on the day of sampling, the sampling period was chosen to be four hours (that is, half a shift) rather than eight hours. Therefore each midwife wore a passive sampling tube for the first four hours of their shift, which was placed on the lapel within the breathing zone. The steel tube was packed with molecular sieve 5A supplied by Markes International, with a diffusive cap on the top. Urine samples were collected at the start of the shift to obtain a baseline measurement; at the end of the four hour monitoring period each midwife provided a second sample. Midwives completed a simple questionnaire, which asked for information on smoking, and alcohol consumption in the past 24 hours, and what medication, if any that the midwife was taking. The questionnaire also asked which delivery rooms the midwife had attended during the monitoring, how many births were involved, and whether nitrous oxide was used. Where nitrous oxide had been used, the midwife was asked to estimate the length of time of use and how long they had been present in the room during use.

At the end of the monitoring period the passive sampling tube was sealed and sent for analysis by thermal desorption and gas chromatography. Environmental sampling tubes were thermally desorbed at $165^{\circ} \mathrm{C}$ in forward flush direction for three minutes with a flow rate of $30 \mathrm{ml} / \mathrm{min}$ helium using a Perkin-Elmer ATD-400. Analysis was performed using a Perkin-Elmer Autosystem XL gas chromatograph. A $60 \mathrm{~m} \times$ $0.32 \mathrm{~mm}$ Gas Pro column was used with inlet pressure of 22 psi helium. The oven programme was: 10 minutes isothermal at $150^{\circ} \mathrm{C}, 250^{\circ} \mathrm{C}$ for 2 minutes post-run; nitrous oxide elutes at 7.2 minutes. Detection was by electron capture at $340^{\circ} \mathrm{C}$. For calibration, a static $2 \%$ gas mixture in air was prepared by syringe addition of $20 \mathrm{ml}$ nitrous oxide to an IL calibrated glass flask. Clean molecular sieve $5 \mathrm{~A}$ tubes were fitted to a spare $1 / 4$ inch GC port and purged with helium. Aliquots of $0.01-10 \mathrm{ml}$ of the diluted nitrous oxide mixture were injected into the calibration tubes.

Abbreviations: TWA, time weighted average; OES, occupational exposure standard 
Main messages

- Personal environmental levels of nitrous oxide exceeded the occupational exposure standard for $70 \%$ of midwife shifts monitored.

- There was a high correlation between environmnental concentrations and biological uptake of nitrous oxide for midwives with no body burden of nitrous oxide at the start of their shift.

- Approximately $50 \%$ of midwives had non-zero baseline values of nitrous oxide in their urine on arrival at the workplace and $50 \%$ of these midwives had very high levels.

- The environmental or occupational determinants of these non-zero baseline values warrants further research.

- Environmental control measures will be required to reduce the high environmental levels observed in practice.

Urine was collected in a sample bottle with a screw cap. Sterile receptacles were provided for convenience of urine collection, with subsequent decanting into the sample bottle. Once the sample had been collected, it was taken to the laboratory, where it was either analysed straight away or put into the freezer. Where samples were taken from the afternoon shift, the second samples were put into a freezer for storage overnight. Determination of nitrous oxide concentration in urine was by headspace analysis and gas chromatography, and followed the procedure published by Sonander and colleagues. ${ }^{14}$ A $10 \mathrm{ml}$ urine sample was taken from the sample bottle directly into a $20 \mathrm{ml}$ gas tight vial equipped with a silicone septum. The gas tight vial was incubated in a water bath at $37^{\circ} \mathrm{C}$ for 20 minutes, and then a $50 \mu \mathrm{l}$ sample of the headspace gas above the urine was taken using a gas tight syringe and injected directly into the gas chromatograph. All such gas chromatograph injections were performed in triplicate. The gas chromatograph was a Hewlett Packard 5890, Series 2, fitted with Electron Capture Detection. An HP Plot Q, $30 \mathrm{~m} \times 0.53 \mathrm{~mm}$ ID column was used; the carrier gas was $5 \%$ methane in argon with molecular sieve and oxygen trap. Conditions were: column flow rate $6 \mathrm{ml} / \mathrm{min}$, split vent $30 \mathrm{ml} / \mathrm{min}$, septum purge $3 \mathrm{ml} / \mathrm{min}$, auxiliary gas $50 \mathrm{ml} / \mathrm{min}$, anode purge $3 \mathrm{ml} /$ min, oven temperature $30^{\circ} \mathrm{C}$, injector temperature $80^{\circ} \mathrm{C}$, and detector temperature $250^{\circ} \mathrm{C}$. The retention time for nitrous oxide was 3.8 minutes. External calibration was performed by injecting $50 \mu \mathrm{l}$ nitrous oxide calibration gas (24 ppm in air) supplied by Alltech. The reproducibility associated with sampling and analysis was determined by taking three samples from a number of individuals on several occasions for each type of sampling.

Ventilation checks were carried out in each of the delivery rooms in both the hospitals monitored, by monitoring the decay of a marker gas using an infrared spectrophotometer. ${ }^{20}$

Data were analysed using the Statistical Package for Social Sciences (SPSS), version 10.

\section{RESULTS}

In the sample of 46 midwives over the four hour measurement period, five midwives had TWA exposures in excess of 10 times the OEL, five in excess of 5 times the OEL, 13 in excess of 2 times the OEL, and of the 46 midwives, only 13 had TWA exposures below the OEL. The interindividual
Policy implications

- High exposures of midwives to nitrous oxide on delivery suites is likely to be widespread in the UK.

- The clearance of nitrous oxide from tissues may take longer than was believed to be the case, which may have implications for the occupational exposure standard for nitrous oxide.

- It may be that exposure to nitrous oxide outside of the workplace is widespread and significant.

environmental concentrations were in the range 2.4$1300 \mathrm{ppm}$, with a mean level of $313 \mathrm{ppm}$ and standard deviation of 358. The coefficient of variation of measurement of repeated samples from an individual was $3-4.8 \%$ over the concentration range $10-150 \mathrm{ppm}$. For urine sampling the coefficient of variation was $6.7 \%$.

In only three midwives was there no nitrous oxide present in the urine after a four hour period. Twenty two midwives had non-zero values of nitrous oxide in their baseline urine samples (that is, immediately before starting their shift); 12 of these had concentrations of nitrous oxide in excess of $27 \mu \mathrm{g} / \mathrm{l}$, which is the biological exposure limit in Italy. In five of these, four from hospital 1 and one from hospital 2, the baseline urine concentrations were higher than those found in the second sample after four hours occupational exposure. We were not able to identify any significant differences between the working environment or work practices between the two hospitals, which could explain why a greater number of midwives in hospital 1 came into this category. The nonzero baseline urinary concentrations were in the range $3-174 \mu \mathrm{g} / \mathrm{l}$, with a mean concentration of $44 \mu \mathrm{g} / \mathrm{l}$ and standard deviation of $51 \mu \mathrm{g} / \mathrm{l}$.

The unexpected observation of non-zero values of nitrous oxide in the baseline urine values of approximately half of the midwives sampled, and of high values for 12 of these raises questions concerning the value of a routine occupational monitoring programme for urinary measurement of nitrous oxide. It also complicates interpretation of the interrelationships between final urinary concentration and personal environmental concentration.

To explore occupational exposure in the total sample, for each individual the baseline value of urinary concentration was subtracted from the final value of urinary concentration. This will skew the data in a manner dependent on the kinetics of tissue clearance of nitrous oxide present in their urine at the start of a shift; a further complication was that for five midwives the baseline urine concentrations were higher than the final concentrations.

Figure 1 presents environmental levels and urinary levels of nitrous oxide for 46 midwives. The relation is described by the regression equation:

\section{Urinary concentration $=0.275 \times$ environmental concentration $(p<0.001)$}

The urinary concentrations in the second urine samples were in the range $0-1102 \mu \mathrm{g} / \mathrm{l}$ (mean $114 \mu \mathrm{g} / \mathrm{l}$, standard deviation $191 \mu \mathrm{g} / \mathrm{l})$. Twenty eight midwives had urinary concentrations in excess of $27 \mu \mathrm{g} / \mathrm{l}$ in their second sample.

The ventilation checks carried out showed that in hospital 1, eight of nine, and in hospital 2, six of 11 did not meet the requirements of 5-6 air changes per hour. ${ }^{9}$ Neither delivery suite had working access to scavenging systems for nitrous oxide. 


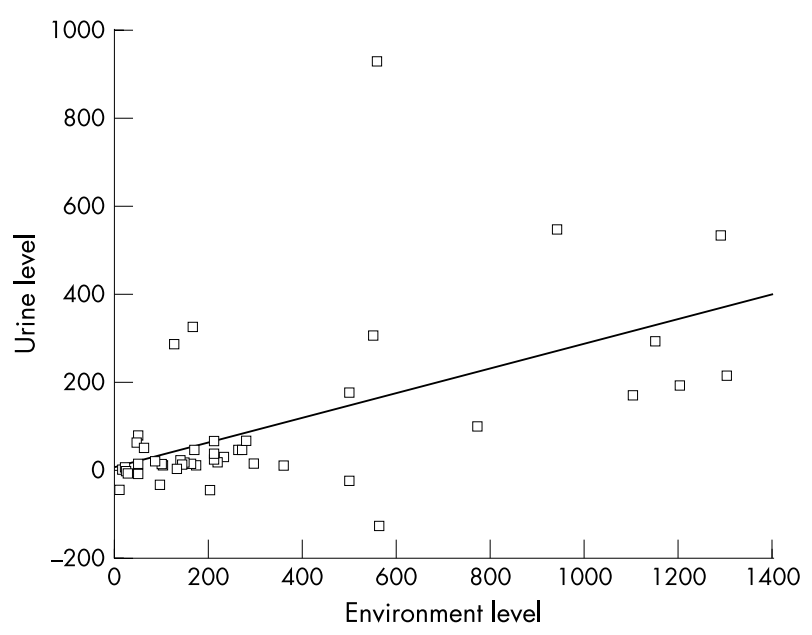

Figure 1 Relation between environmental and urinary levels of nitrous oxide.

Out of the 46 midwife shifts monitored, on six occasions the midwife attended two delivery rooms, and therefore correlation between exposure and the ventilation of the delivery rooms was not possible. For the remaining 40 midwife shifts monitored, the midwife remained in one delivery room for the duration of the monitoring period. In hospital 1 , the midwife only attended one delivery room on 11 monitoring occasions. All the rooms monitored had ventilation rates below those recommended. In hospital 2, the midwife only attended one delivery room on 29 monitoring occasions. Of the delivery rooms monitored, four had ventilation rates below those recommended.

\section{DISCUSSION}

Nitrous oxide is considered to be of low solubility in blood or in other biological tissues. During absence overnight from the work environment, occupational dose should be completely cleared out of the body storage reservoirs.

We found that approximately half of our samples of 46 midwives had non-zero baseline values of nitrous oxide in urine, of which 12 had very high levels.

The kinetics of absorption of nitrous oxide and then tissue clearance are not known quantitatively. It is known that nitrous oxide is eliminated in the kidney by a diffusion process determined by the equilibration of partial pressures in urine and plasma. As a result, the concentration of nitrous oxide in urine is independent from urine output, and urine leaving the kidneys equilibrates with gas in arterial blood with the bladder serving as a collecting and mixing vessel. Thus urinary concentration can be considered as an integrator over time, which indicates uptake over the duration of exposure.

Pre-shift urine samples were collected as soon as the midwife appeared on the delivery suite. Since urinary concentration is an integrator over time, any brief adventitious exposure of a midwife to nitrous oxide between entry to the hospital and reporting to the delivery suite is highly unlikely to have altered the concentration in the urine in the bladder.

It has been suggested in the literature that certain Gram negative bacilli which may be present in the urinary tract during urinary tract infections (UTI) can produce nitrous oxide. However, the prevalence of high levels of nitrous oxide in our sample of midwives is much higher than the prevalence of UTI in women; furthermore, not all UTI is caused by Gram negative bacilli. It is therefore unlikely that UTI is the source of high baseline levels in urine prior to the commencement of the shift.
Other possibilities are non-occupational exposure to nitrous oxide, for example, from gas fires in the home, motor vehicle exhaust gases, or from spray cans for foodstuffs or deodorants. Given the ubiquity of these sources of exposure, if they were contributing to the high baseline levels of nitrous oxide in urine observed in 22 women, we would not expect 24 women to have an absence of nitrous oxide in their baseline urine. The most likely explanation of nitrous oxide in baseline urine is perhaps that tissue clearance occurs over much longer time periods than has been previously thought. Thus the 22 non-zero baseline values may relate to previous but recent occupational exposure. The 24 zero baseline values would then relate to women who have not been as recently occupationally exposed, and there may be an unrecognised accumulating effect of exposure.

The presence of nitrous oxide in baseline urine complicates an evaluation of the relations between environmental exposure and uptake as measured by urinary concentrations. In order to explore this, the group of 24 midwives with no nitrous oxide in their baseline have been analysed separately, as well as examining the group as a whole.

For the 24 midwives there was a high correlation between personal environmental exposure and urinary concentrations. This shows that a TWA personal environmental sample is a good measure of integrated biological uptake for women with no nitrous oxide in their urine at baseline.

The occupational exposure limits in the UK relate to environmental levels, but ideally these should relate to the measure that actually reflects uptake-that is, urinary concentration. These data show that there is a need to explore the kinetics of nitrous oxide absorption over the sort of time scales of relevance in occupational health practice. This will require tracking a number of individuals over a period of days, spanning both occupational exposure days and non-occupational exposure days. Urine could be sampled periodically, and the role of accumulated uptake and washout explored on the basis of shift pattern and exposure.

\section{CONCLUSION}

Monitoring for nitrous oxide exposure by personal environmental sampling using passive diffusion tubes, or by collection of urine samples, was found to be acceptable to midwives and was convenient. The use of analytical gas chromatography for determination of nitrous oxide in urine samples and environmental samples is accurate and sufficient for this purpose. The reproducibility of each type of sampling was also satisfactory. Our data show that midwives are routinely exposed to levels of nitrous oxide in excess of the occupational exposure limit (OEL). Environmental control measures and/or changes in work practices will be necessary to reduce the high environmental levels observed; environmental monitoring may be undertaken to check the efficacy of such measures in reducing environmental levels.

There is a high correlation between environmental exposure measurements and measures of biological uptake (that is, urinary concentrations) for midwives with no nitrous oxide in their urine at the commencement of their shift. However, we observed approximately half of the midwives studied to have significant levels of nitrous oxide in their urine at baseline. Thus it would appear that nitrous oxide is not cleared from the body as quickly as previously thought. Consequently, depending on exposure patterns and shift patterns, an individual may accumulate body burden of nitrous oxide. This may occur for an individual, even if environmental measurement falls below the OEL. We suggest that urine samples pre- and post-shift will allow a reliable estimate of nitrous oxide exposure for persons who have none detectable in the pre-shift sample. In the case of nitrous 
oxide being present in the pre-shift sample, the possible reasons, including bioaccumulation with the potential for increased susceptibility to adverse effects, should be considered.

Quantification of the clearance of nitrous oxide from the body would permit personal occupational uptake to be measured by biological monitoring.

\section{ACKNOWLEDGEMENTS}

We would like to thank Mrs Brenda Rees and Mrs Anne Morgans, together with all the midwives who took part in this study. We would also like to thank Markes International for supplying the sampling tubes, and the Health and Safety Laboratory in Sheffield for the analysis of the personal environmental samples.

\section{Authors' affiliations}

K A Henderson, Health, Safety and Environment Unit, University of Wales College of Medicine, Heath Park, Cardiff CF14 4XN, UK

I P Matthews, Department of Epidemiology, Statistics and Public Health, University of Wales College of Medicine, Heath Park, Cardiff CF14 4XN, UK

A Adisesh, Occupational Health Department, Trafford General Hospital, Moorside Road, Davyhulme, Manchester M41 5SL, UK

A D Hutchings, Department of Pharmacology, Therapeutics and Toxicology, University of Wales College of Medicine Academic Centre, Llandough Hospital, Cardiff, UK

\section{REFERENCES}

1 Rowland AS, Baird DD, Weinberg CR, et al. Reduced fertility in women employed as dental assistants exposed to high levels of nitrous oxide. N Engl J Med 1992;327:993-7.

2 Baird PA. Occupational exposure to nitrous oxide-not a laughing matter. N Engl J Med 1992;327:1026-7.

3 Kugel G, Letelier C, Attallah $\mathrm{H}$, et al. Chronic low level nitrous oxide exposure and infertility. J Dent Res 1989;68:313.
4 Hemminki K, Kyyronen P, Lindbohm ML. Spontaneous abortions and malformations in the offspring of nurses exposed to anaesthetic gases, cytotoxic drugs and other potential hazards in hospital based on registered information of outcome. J Epidemiol Community Health 1985:39:141.

5 Monson RR. Occupation and reproduction. Occupational epidemiology. BOCA Raton: CRC Press, 1990:188.

6 Alhborg JR, Axelsson G, Bodin L. Nitrous oxide exposure and subfertility among Swedish midwives. Int J Epidemiol 1996;25:783-90.

7 Schumann D. Nitrous oxide anaesthesia: risks to health personnel. Int Nurs $\operatorname{Rev}$ 1990;37:214-17

8 HMSO. Control of Substances Hazardous to Health (COSHH) Regulations: Approved Codes of Practice. London: HMSO, 1999

9 Health Services Advisory Committee (HSAC). Anaesthetic agents: controlling exposure under COSHH. HSAC, 1996.

10 Munley AJ, Railton R, Gray WM, et al. Exposure of midwives to nitrous oxide in four hospitals. BMJ 1986;293:1063-4.

11 Newton C, Fitz-Henry J, Bogod D. The occupational exposure of midwives to nitrous oxide-a comparison between two labour suites. Int J Obstet Anaesth 1999;8:7-10.

12 Henderson KA, Matthews IP. An environmental survey of compliance with occupational exposure standards (OES) for anaesthetic gases. Anaesthesia 1999:54:941-7.

13 Trevisan A, Gori GP. Biological monitoring of nitrous oxide exposure in surgical areas. Am J Ind Med 1990;17:357-62.

14 Sonander $\mathrm{H}$, Stenquist $\mathrm{O}$, Nilsson K. Urinary nitrous oxide as a measure of biologic exposure to nitrous oxide anaesthetic contamination. Ann Occup Hygiene 1983;27:73-9.

15 Imberti R, Preseglio I, Imbriani $M$, et al. Low flow anaesthesia reduces occupational exposure to inhalation anaesthetics. Acta Anaesthesiol Scand 1995;39:586-91.

16 Imbriani M, Ghittori S, Pezzagno G. The biological monitoring of inhalation anaesthetics. Gionale Italiano Di Medicina Del Lavoro Ed Ergonmia 1998:20:44-9.

17 Gobba F, Ghittori S, Imbriani M, et al. The urinary excretion of solvents and gases for the biological monitoring of occupational exposure: a review. The Science of the Total Environment 1997;199:3-12.

18 Accorsi A, Barbieri A, Raffi G, et al. Biomonitoring of exposure to nitrous oxide, sevoflurane, isoflurane and halothane by automated GC/MS headspace urinalysis. Int Arch Occup Environ Health 2001;74:541-8

19 Imbriani M, Ghittori S, Pezzagno G, et al. Nitrous oxide in urine as biological index of exposure in operating room personnel. Applied Industrial Hygiene 1988:3:223-7.

20 MDHS 73. Measurement of air change rate in factories and offices. Croner, 1992. 